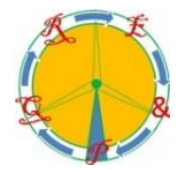

\title{
Impact of Distributed Generation and Energy Storage on Power Quality
}

\author{
Gimenes, T. K. ${ }^{1}$, Mendes, P.R. ${ }^{1}$, Ledesma, J. J. G. ${ }^{2}$, and Ando Junior, O. H. ${ }^{1,2}$ \\ ${ }^{1}$ Department of Electrical Engineering \\ State University of Paraná Western \\ Av. Tancredo Neves, 6731. Foz do Iguaçu - Paraná (Brazil) \\ e-mail: thayana.gimenes@unioeste.br,poliana.mendes@unioeste.br \\ ${ }^{2}$ Department of Renewable Energies \\ UNILA, Federal University of Latin American Integration \\ Av. Sílvio Américo Sasdelli, 1842. Foz do Iguaçu-PR (Brazil) \\ Phone/Fax number: +55 45 3576-73.07, e-mail: jorge.ledesma@unila.edu.br, oswaldo.junior@unila.edu.br
}

\begin{abstract}
With electricity demand increase and the need to expand and diversify generating sources in pursuit of energy sustainability, the distributed generation (DG), from unconventional renewable sources, has been getting more and more space in the distribution system (DS). In Brazil, this DG dissemination is predominantly photovoltaic solar energy (PV) due to the characteristics and high levels of solar radiation. As this type of source depends on solar irradiation for energy conversion, the PV system is directly influenced by cloudiness, which causes part of the solar incidence to reflect in the clouds and may cause a drastic and abrupt reduction of the generated power. This phenomenon is difficult to predict, thus making PV systems an intermittent and considered supplementary source. Moreover, as it is an electronically processed generation source for power conversion and adequacy, there is the incidence of harmonic injection in the distribution network at the connection point. Due to the possible problems that DG can cause in DS, this paper presents an analysis of the impact on power quality (PQ) of a DS, considering different allocations, penetration levels, and system load. The study focus is on the Brazilian DS, so the system was adapted to the local reality through real dealership data.
\end{abstract}

Key words. Distributed System, Power Quality, Distributed Generation, Photovoltaics, Renewable Energy.

\section{Introduction}

Distribution System has been undergoing a paradigm and operation change with the insertion of DG, whose impacts and benefits are the object of study [1]. The DG has a benefit for DS operation, such as loss reduction, voltage support and reduction of the power transferred by the distribution and transmission lines [1, 2]. All these benefits contributed to the growth of this technology. Another benefit of DG is the diversity of generation sources that can be used. These sources may be $(i)$ nonrenewable; as combustion generator, the diesel generator has being the most commonly used, turbines operating on natural gas, propane or vegetable oil and combustion turbines [3], [4], [5]; or (ii) renewable, where the main ones are solar photovoltaic (PV); wind sources, biomass and small hydroelectric plants [3]. Due to environmental concerns, the generation technologies that gained the most space in recent years were those that use renewable energy sources.

The most used renewable source is the PV. Currently, in the world the installed power is $510 \mathrm{GW}$, where around $100 \mathrm{GW}$ were installed in the year 2018. In the year 2000 the power of PV was very small, less than $10 \mathrm{GW}$. The increase began in the end of the decade and gained more strength in the early 2010s. The number of PV plants each years gains a considerable increase and in 2018 the country that most invested was China, having installed $45 \mathrm{GW}$ of the $100 \mathrm{GW}$ worldwide [6].

In Brazil, the situation is not different. In 2018 the installed capacity of DG was $669.6 \mathrm{MW}$, an increase of almost $300 \%$ over the year 2017, which had 246.1 MW. Of the total installed there is a share of PV solar energy of $526 \mathrm{GWh}$ generation and $562 \mathrm{MW}$ of installed power, which represents $84 \%$ of DG installed in Brazil.[7].

Although widely used in the world, the PV have some issues, where the main is the intermittence, once the panels depend on weather conditions for power generation. This means that the power generated may vary sharply over a period of time, causing voltage and frequency fluctuation [8]. In order to minimize the effect of voltage fluctuation, energy storage systems (ESS) have been used in conjunction with $\mathrm{PV}$, which makes it possible to better manage energy and is used as an auxiliary unit to smooth out voltage fluctuations as well to store surplus energy in the ESS. This will make the system more stable and reliable [9-11]. According to [11] the most suitable ESS for this application, considering the power density, charge-discharge capacity, efficiency, service life and cost effectiveness, are the chemical storage, mainly the batteries [12,-14].

However, with the high DG and ESS penetration in DS, have up insertion of electromagnetic disturbances and issues with voltage and frequency instability of the 
distribution system that has a negative impact in power quality. Among the inserted disorders originated by DG, the following stand out: $(i)$ voltage imbalance, caused by to single-phase generation connection; (ii) harmonic distortion, caused by the use of frequency converters; and (iii) voltage fluctuations, caused by intermittent generation [2], [14].

Despite being an incipient technology, it is convinced that the dissemination of DG and ESS in the Brazilian DS is inevitable so that it is possible to promote safety and energy sustainability. Therefore, this paper seeks to analyze the impacts of distributed photovoltaic generation and batteries on the distribution system. Different scenarios of loading, penetration and allocation of DG were analyzed. The system analyzed were the modified IEEE 34 bus and the simulation will be done in ATPDraw. With this work, it intends to understand what happens to DS from the point of view of PQ, when there is penetration of DG and ESS.

\section{Power Quality: Overview}

Power Quality is defined as the measure of how well electric power can be used by consumers [15]. For a long time, this only meant that electricity should be supplied continuously. However, with the technological advancement that resulted in the increase of electronically controlled devices and increase of system load, from the end of the 80'sthe concern with the PQ increased[16].

The Electronic devices operate on direct current and the power system uses alternate current, so these devices require equipment that can transform the system current. Due to the use of these equipment, electromagnetic disturbances are inserted in the power systems. So, it is necessary to create parameters to be followed, in order to have the least possible disturbance insertion.

Due to the onset of these disorders there is a need for regulation of the $\mathrm{PQ}$. International organizations have standards that regulate the PQ, bringing definition, measurement procedures and acceptable levels of disturbances, the main ones being IEC 61000 and IEEE 1159. IEEE still has a specific harmonic standard, IEEE 519. The European Union is the region that presents the greatest advance regarding the standardization of the PQ, in its set of standards EN is the current EN 50160 standard, which was created in 1994 and has been constantly updated [17][18].

In the Brazilian scenario, the rules regarding distribution systems are found in PRODIST (Distribution Procedures). This document is divided into 11 modules and each module has standards for something related to DS. Power Quality standardization is in module 8. It provides definitions and benchmarks for both quality of service and product quality.

\section{A - Module 8-Prodist}

Module 8 was first approved in 2008 and has since undergone 10 updates. This module is responsible for the standardization of the PQ and presents the definitions, procedures for measuring disturbance and the limit values. It shows the following parameters: $(i)$ steady state voltage; (ii) power factor; (iii) harmonic distortion;(iv) voltage imbalance; $(v)$ voltage fluctuation; (vi) voltage variation; and (vii) short-term voltage variation [19].

The parameters analysed in this work will be addressed, which are voltage variation in steady state, harmonic distortion and voltage imbalance

Steady State Voltage: In this topic the appropriate, precarious and critical limits for steady state voltage are established. The limits are divided according to the voltage nominal values, being the divisions, $(i)$ equal to or greater than $230 \mathrm{kV}$, (ii) between $69 \mathrm{kV}$ and $230 \mathrm{kV}$, (iii) between $1 \mathrm{kV}$ and $69 \mathrm{kV}$ e (iv) below $1 \mathrm{kV}$. For voltage levels above $69 \mathrm{kV}$ it is considered suitable if the voltage is between 0.95 p.u to 1.05 p.u.. For voltage between $1 \mathrm{kV}$ and $69 \mathrm{kV}$ a suitable voltage is between 0.93 and 1.05 p.u.. For voltage equal $220 \mathrm{~V}$ appropriate values are between 202 and $231 \mathrm{~V}$, and for a rated voltage of $127 \mathrm{~V}$ appropriated values are between 117 and $133 \mathrm{~V}$.

Harmonic Distortion: In this topic the terminology, expression for the calculation of harmonic distortion and the limits for total and individual distortion are established. Prodist only presents limits for total voltage distortion

For buses with nominal voltage less than $1 \mathrm{kV}$ PRODIST sets a limit of $10 \%$ of total voltage distortion (DTT), while for buses with nominal voltage between 1 $\mathrm{kV}$ and $13,8 \mathrm{kV}$ the limit is $8 \%$. Buses with nominal voltage between $13,8 \mathrm{kV}$ and $69 \mathrm{kV}$ must have a DTT of up to $6 \%$, and systems between $69 \mathrm{kV}$ and $230 \mathrm{kV}$ up to $3 \%$. Thus, it is a less conservative norm than the others, where generally considered one 5\% DTT de 5\% and also limits for current distortion [20] [21]

Voltage Imbalance: The topic concerning voltage imbalance also presents definitions, terminology and expressions for calculation. The limit set by the PRODIST follows the IEEE and IEC standards of $2 \%$ [22] [23].

The limits of voltage and harmonic distortion allowed by PRODIST are exemplified in Fig 1 .

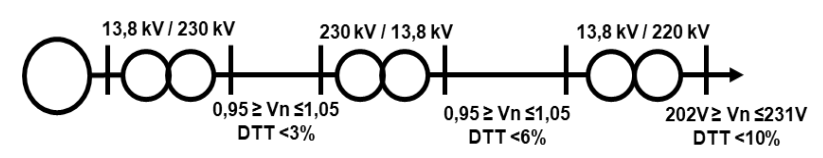

Fig 1: Voltage Range and Harmonic Distortion Limits

\section{Modeling and Suitability of the IEEE 34 Bar Distribution System}

The objective of this work is to verify if the location and penetration of distributed generation and energy storage significantly impact in the harmonic distortion and voltage unbalance also on the voltage support of a distribution system. For this, the work was divided into 3 steps.

STEP 1: it was made the choice of the distribution system to be studied and the software that will be used in the simulations. For the choice of the system it was taken into consideration the characteristics necessary for the study and the availability of data necessary for the use of the system. Based on this, the IEEE 34 bar distribution system [24] was chose, presented in Fig 2. 


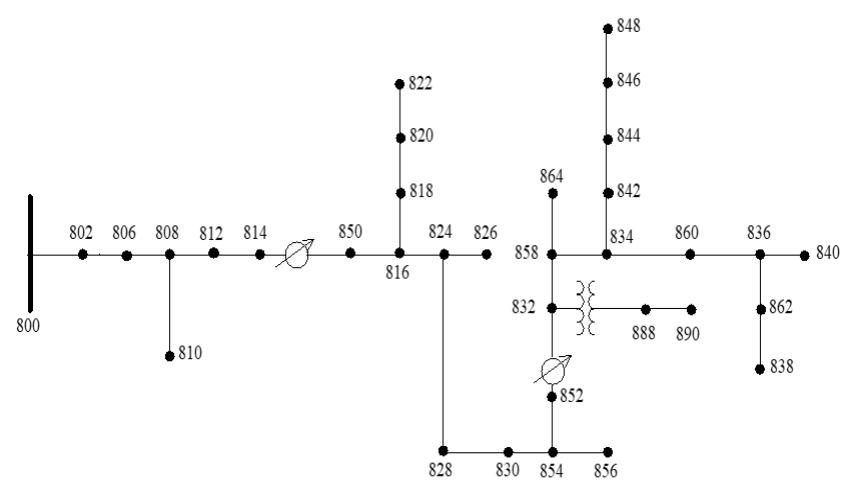

Fig 2: IEEE 34 bar system.

For a better representation of a DS, 3 low voltage $(380 / 220 \mathrm{~V})$ branches of different impedances and loads were added, shown in Fig 3. The original systems were balanced, but were forced to be unbalanced to preserve the characteristics of the low voltage systems.
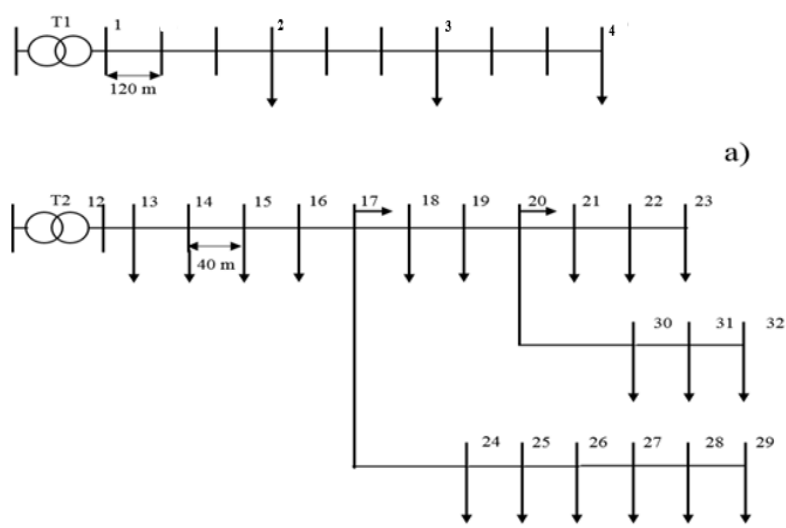

b)

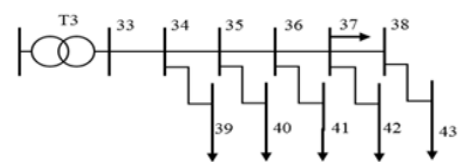

c)

Fig 3: Low Voltage Branches

To perform the simulations, ATPDraw was chosen, since the software is widely used in power quality studies. In addition, to the ease of working on the graphical interface, without prior knowledge of programming, another point considered was the software being free to access.

STEP 2: Computational modeling of medium and low voltage systems, distributed generation and batteries was performed. The generator was modeled as an ideal source in series with its impedance. The transformers were modeled as saturated models. For the distribution lines, the concentrated $\Pi$ model was chosen. This has been adopted since for medium voltage systems the mutual impedances are given. System loads were modeled as impedances to simplify the model. The 34-bar system has loads distributed on the distribution lines, in the model used these loads were considered concentrated on the bars, for this the load was equally divided between the bars on which the line was connected.
For distributed generation and battery modeling, a simplified model was considered, where only the inverter output is required. Thus, DG and batteries were modeled as a current source. The current entered or consumed by these elements has been modeled as a fundamental frequency current source in parallel with current sources at the integer multiple frequencies of the fundamental frequency, representing the harmonic currents inserted by the inverter. This model was chosen because it is sufficient for the proposed analysis and to simplify the system implementation. It is not necessary to implement the complete inverter.

STEP 3: It was consisted of simulations and analysis of results. The simulations were made by first varying the position of the DGs and the Batteries, then varying the system load and finally the level of DG penetration in the system. In Fig 4 is presented the cases that will be analyzed.

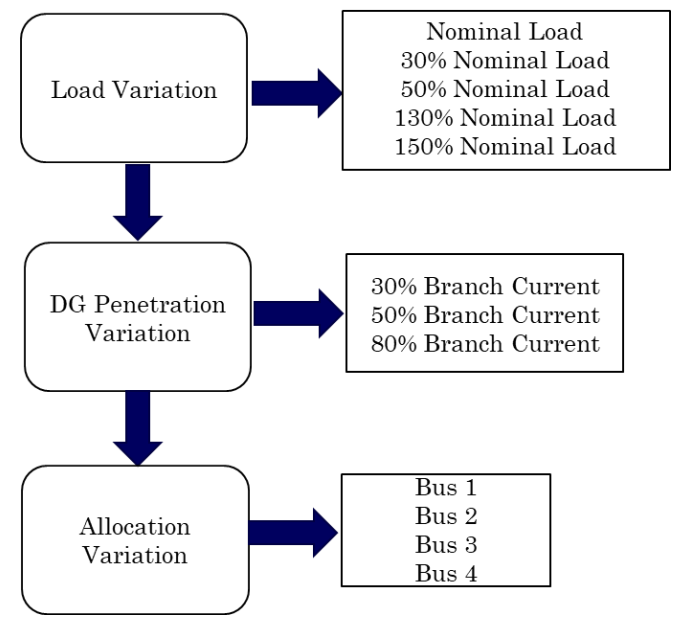

Fig 4: Simulated Cases

\section{Scenarios and Analysis Proposed IEEE 34-buses distribution system}

Based on the system implemented for analysis purposes, the following parameters and system operating conditions are used: (i) The load will increase from $30 \%$ to $150 \%$; (ii) DG penetration will be $30 \%, 50 \%$ and $80 \%$ of system load for all demand levels and (iii) The inverter is inserted the maximum harmonics that ABNT NBR 16149 allows. The values are presented in Table 1 .

Table 1:- Harmonic Input Limits for Inverters

\begin{tabular}{|c|c|}
\hline Harmonic Order & Maximum limit \\
\hline Odd $-3^{\mathrm{a}}$ to $9^{\mathrm{a}}$ & $4.0 \%$ \\
\hline Odd $-11^{\mathrm{a}}$ to $15^{\mathrm{a}}$ & $2.0 \%$ \\
\hline Odd $-17^{\mathrm{a}}$ to $21^{\mathrm{a}}$ & $1.5 \%$ \\
\hline Odd $23^{\mathrm{a}}$ to $33^{\mathrm{a}}$ & $0.6 \%$ \\
\hline Even $-2^{\mathrm{a}}$ to $8^{\mathrm{a}}$ & $1.0 \%$ \\
\hline Even $-10^{\mathrm{a}}$ to $32^{\mathrm{a}}$ & $0.8 \%$ \\
\hline
\end{tabular}

The load and generation conditions were chosen in order to have different possible scenarios and to understand how the variation of these parameters influence the inserted disturbances. The condition of the inverter to enter the maximum harmonic limit is justified to work with the worst case scenario. The transmission 
system has two capacitors bank that shust off when operating at light load. The low voltage extensions were connected to bars 850,854 and 860 respectively as shown in Fig 5.

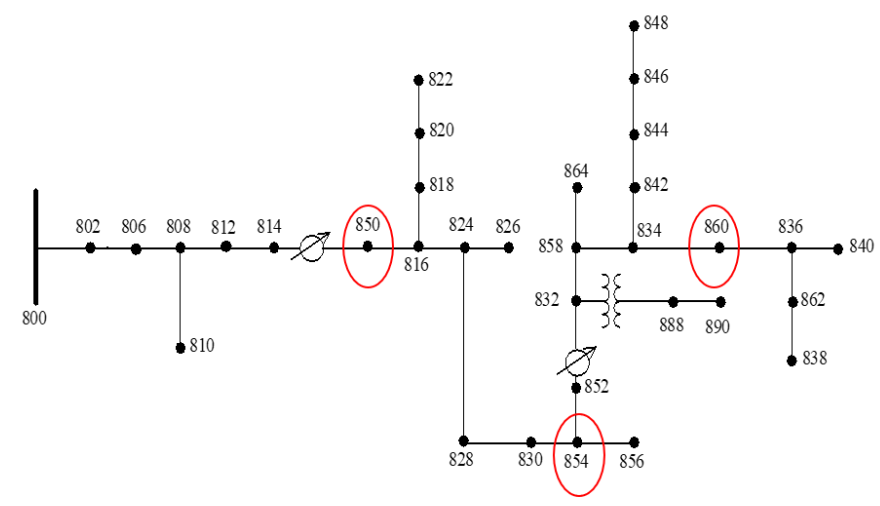

Fig 5: Buses connected to Low Voltage Branches

The first scenario to be studied will be the load variation for the same allocation and $30 \%$ of the value of branch current of DG penetration, besides the battery acting as a voltage support. The parameters analyzed will nbe voltage imbalance, voltage levels and total harmonic current distortion. In Fig 7 is shown the imbalance factor of load buses of branch 1 of system without DG and BES. In Fig 7 is presented the imbalance factor for system with DG and BES.

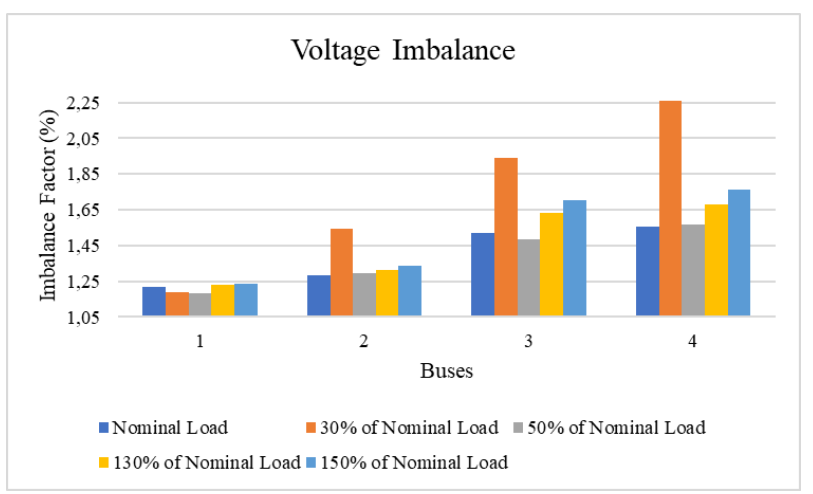

Fig 6: Voltage Imbalance without DG and BES

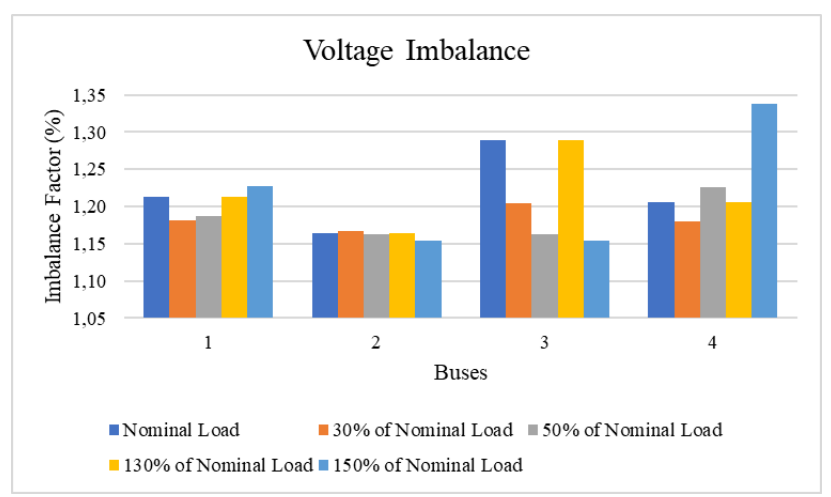

Fig 7: Voltage Imbalance with DG and BES

It's possible to notice that the distributed generation and batteries assist in the voltage imbalance of the distribution system of which they are part. Both DG and BES are three phase.
In Fig 8 and Fig 9 is presented, respectively, the voltage level for system without and with DG and BES.

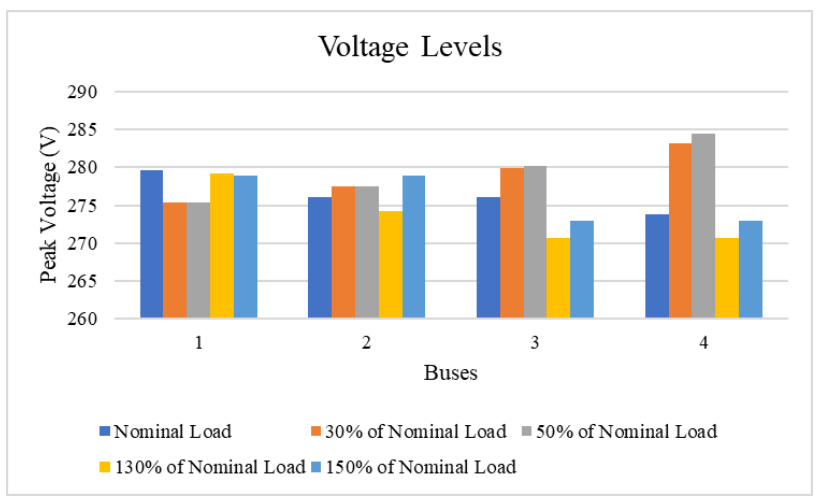

Fig 8: Voltage Levels without DG and BES

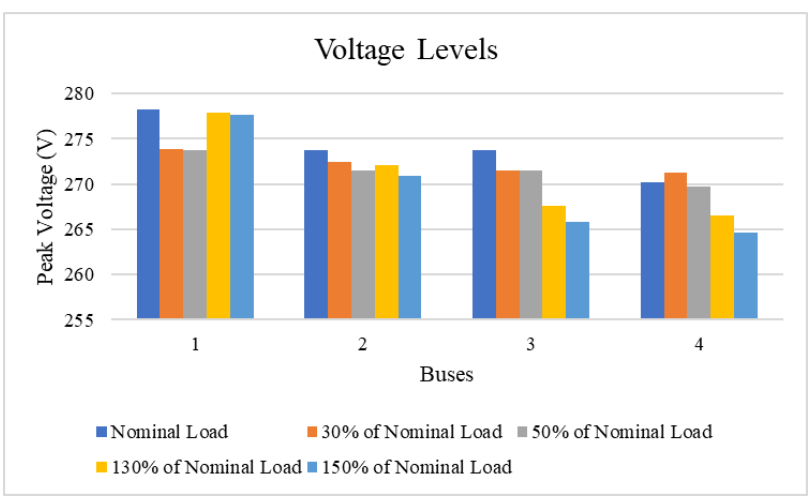

Fig 9: Voltage Levels with DG and BES

The DG and BES provide voltage support, however, the impedance values depend directly on the frequency. Thus, the insertion of non-linear elements in the system causes the insertion of a harmonic, with that the impedance value can vary and cause a greater voltage drop. The total harmonic distortion is shown in Fig 10.

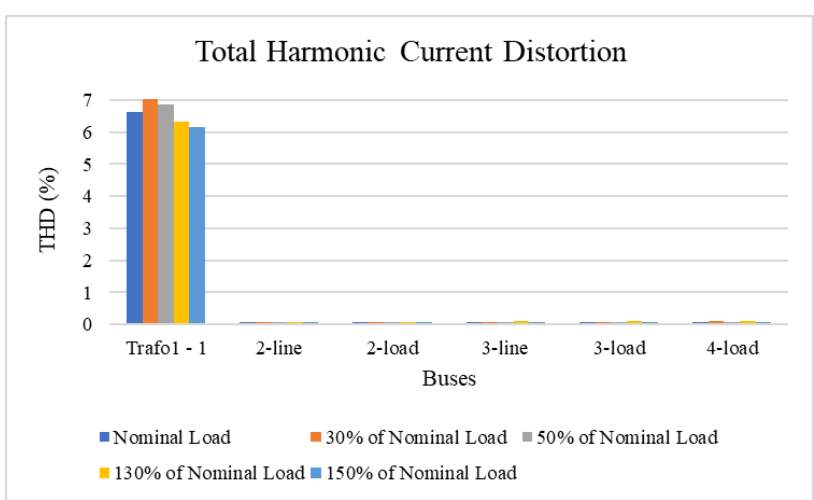

Fig 10: Total Harmonic Distortion

The system does not have non - linear loads, therefore the total of harmonics comes from the distributed generation and batteries. The harmonics are absorbed by the system, so they do no affect the loads of distribution system.

The second scenario analyzed was the distributed generation penetration variation. In the Fig 11 is presented the imbalance factor considering three different penetrations of DG. 


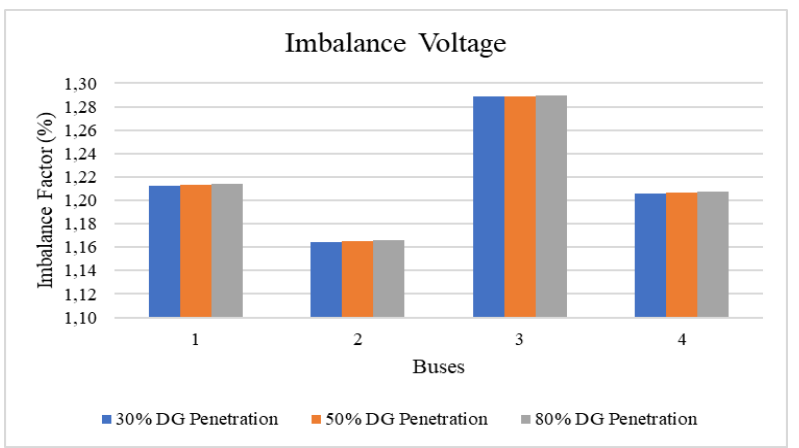

Fig 11: Voltage Imbalance

It is possible to realize that penetration variation does not interfere in voltage imbalance, this is because the DG used is three phases. In Fig 12 is shown the voltage level.

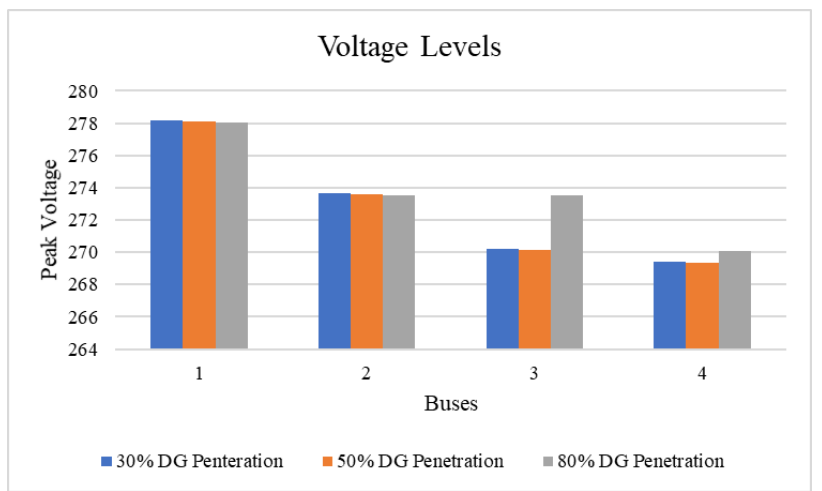

Fig 12: Voltage Levels

Through the graph, it can be seen that a greater penetration of distributed generation Will contribute to a higher voltage increase, this occurs because the voltage support Will be larger, especially in the bars farther electrically from the generation system. Low DG penetration can be negligible for the system, making the voltage support minimal. The graph of harmonics is presented in Fig 13.

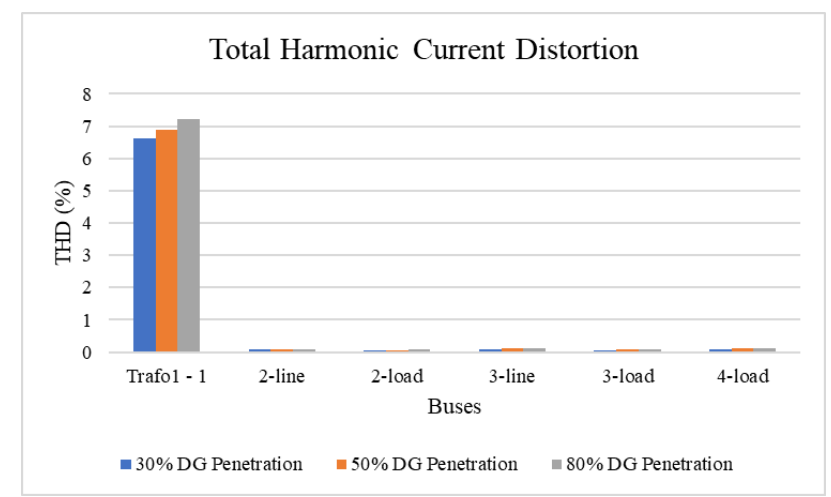

Fig 13: Total Harmonic Distortion

As expected, the harmonic distortion increase with the increased penetration of DG and that distortion is absorbed by the system.

The last scenario analyzed is the variation of the allocation of DG and BES. The results will be presented next. The voltage imbalance is presented in Fig 14

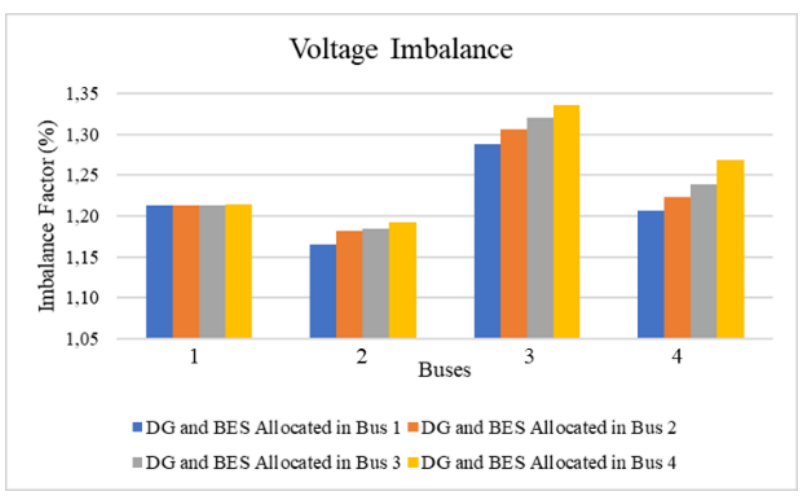

Fig 14: Voltage Imbalance

The smallest imbalance factor occurs when DG and BES are in bus 1 . In the transformer bus the imbalance factor don't change regardless of equipment location.

In the Fig 15 is presented voltage level considering different allocation of DG and BES.

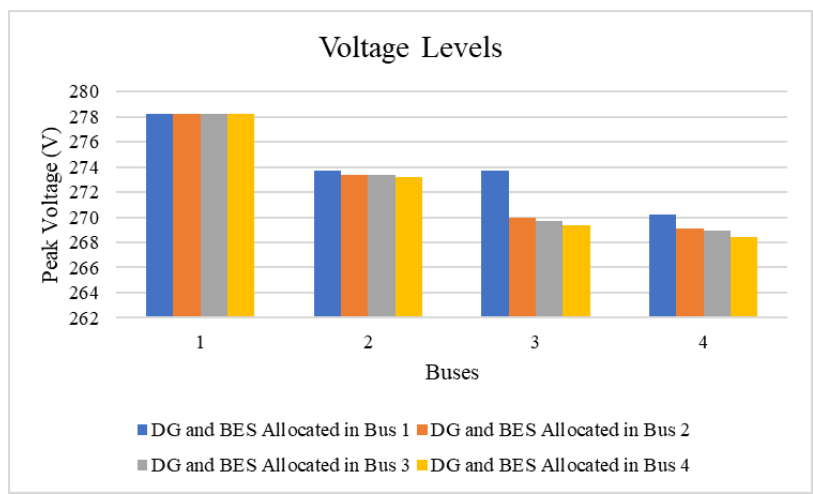

Fig 15: Voltage Levels

The voltage support is better when DG is allocated on the nearest transformer bus, once the voltage support occurs in the first system bus consequently the voltage in the other buses will increase.

The last parameter to be analyzed is the total harmonic distortion, that is shown in Fig 16.

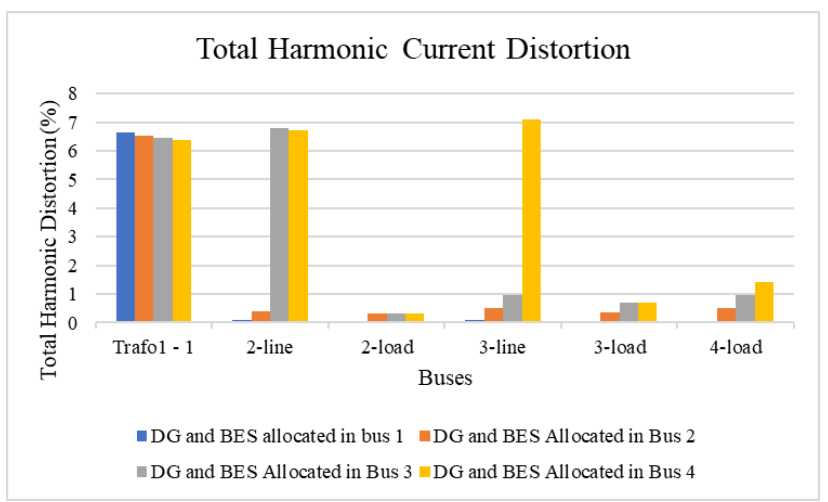

Fig 16: Total Harmonic Distortion

How harmonic distortion is absorbed by the system, the farther from the transformer the distributed generation and batteries are, the more distortion will impact the distribution system, as can be seen in the graph above. Thus, the closer the transformer DG and BES are, the less impact the harmonics caused on the distribution system. 


\section{Considerations}

Through this article it was possible to realize that the insertion of distributed generation and storage of energy present advantages for the electrical system, mainly regarding the voltage acting as a voltage support and thereby improving the system voltage profile and attenuating the voltage unbalance. However, there are disadvantages, such as the insertion of harmonics.

Studying the allocation of distributed generation and batteries can mitigate the disturbances caused by them. For the cases analyzed in this article, the allocation of these equipment closer to the distribution transformer contributes for less disturbance insertion and greater voltage support.

\section{Acknowledgement}

This research was funded by Triple Agenda Institutional Program of the Federal University of Latin American Integration (UNILA), grant number Edital PRPPG 137/2018. Ando Junior, O.H. was funded by the Brazilian National Council for Scientific and Technological Development (CNPq), grant number 307223/2017-5 and 407531/2018-1.

The authors is grateful to the Federal University of Latin American Integration (UNILA), Coordination for the Improvement of Higher Education Personnel (CAPES), Brazilian Council for Scientific and Technological Development $(\mathrm{CNPq})$ and and to the Applied Technology and Innovation Institute (ITAI).

Gimenes, T. K. is grateful to the ITAIPU Technological Park (PTI) for the post-graduation scholarship awarded. The project was developed under the COPEL program "Research and Development", regulated by ANEEL (PD-2866-0452/2017). The authors would like to thanks COPEL for support and facilities.

\section{References}

[1] G. Pepermans, J. Driesen, D. Haeseldonckx, R. Belmans, and W. D'haeseleer, "Distributed generation: Definition, benefits and issues," Energy Policy, vol. 33, no. 6, pp. 787-798, 2005.

[2] P. P. Barker and R. W. De Mello, "Determining the impact of distributed generation on power systems. I. Radial distribution systems," Power Eng. Soc. Summer Meet. 2000. IEEE, vol. 3, no. c, pp. 1645-1656 vol. 3, 2000.

[3] T. Ackermann, G. Andersson, and L. Söder, "Distributed Generation: A Definition,” Eletr. Power Syst. Res., vol. 7796, pp. 195-204, 2001.

[4] P. Paliwal, N. P. Patidar, and R. K. Nema, "Planning of grid integrated distributed generators: A review of technology, objectives and techniques," Renewable and Sustainable Energy Reviews, vol. 40. Elsevier, pp. 557-570, 2014.

[5] W. El-Khattam and M. M. A. Salama, "Distributed generation technologies, definitions and benefits," Electr. Power Syst. Res., vol. 71, no. 2, pp. 119-128, 2004.

[6] Internacional Energy Agency - IEA, "Snapshot of Global PV Markets," 2019.

[7] Empresa de Pesquisa Energética, "Balanço Energético Nacional 2019," 2019.

[8] C. S. Lai, Y. Jia, L. L. Lai, Z. Xu, M. D. McCulloch, and K. P. Wong, "A comprehensive review on large-scale photovoltaic system with applications of electrical energy storage," Renew.
Sustain. Energy Rev., vol. 78, no. November 2016, pp. 439 451, 2017.

[9] J. Kondoh et al., "Electrical energy storage systems for energy networks," Energy Convers. Manag., vol. 41, no. 17, pp. 1863-1874, 2000.

[10] K. C. Divya and J. Østergaard, "Battery energy storage technology for power systems-An overview," Electr. Power Syst. Res., vol. 79, no. 4, pp. 511-520, 2009.

[11] V. Silvera, D. A. Cantane, R. Reginatto, J. J. G. Ledesma, M. H. Schimdt, and O. H. Ando Junior, "Energy Storage Technologies towards Brazilian Electrical System," Renew. Energy Power Qual. J., vol. 1, no. 16, pp. 380-386, 2018.

[12] S. Shivashankar, S. Mekhilef, H. Mokhlis, and M. Karimi, "Mitigating methods of power fluctuation of photovoltaic (PV) sources - A review," Renew. Sustain. Energy Rev., vol. 59, pp. 1170-1184, 2016.

[13] P. F. Ribeiro, B. K. Johnson, M. L. Crow, A. Arsoy, and Y. Liu, "Energy storage systems for advanced power applications," Proc. IEEE, vol. 89, no. 12, pp. 1744-1756, 2001.

[14] A. Kalair, N. Abas, A. R. Kalair, Z. Saleem, and N. Khan, "Review of harmonic analysis, modeling and mitigation techniques," Renew. Sustain. Energy Rev., vol. 78, no. April, pp. 1152-1187, 2017.

[15] S. M. Deckmann and J. A. Pomilio, Avaliação da Qualidade da Energia Elétrica. 2018.

[16] R. C. Dugan, M. F. McGranaghan, S. Santoso, and H. W. Beaty, Electrical Power Systems Quality, Segunda Ed. McGraw - Hill, 2004.

[17] E. Unidos, "Nota Técnica SRD-105 - Anexo I - Relatório Técnico 1/8."

[18] O. H. Ando Junior, A. S. Bretas and R. C. Leborgne, "Methodology for Calculation and Management for Indicators of Power Quality Energy," in IEEE Latin America Transactions, vol. 13, no. 7, pp. 2217-2224, July 2015. doi: 10.1109/TLA.2015.7273780Revisão 10, 2018.

[20] IEEE, "IEEE Std 519-1992 Recommended Practices and Requirements for Harmonic Control in Power Systems," 1992, pp. 1-112.

[21] IEC, "Electromagnetic compatibility (EMC) - Part 3-2: Limits for harmonic current emissions (equipment input current $<16$ A per fase)," 2009.

[22] IEC, "Eletromagnetic compatibility - Part 3-13: Limits Assessment of emission limits for the connection of unbalanced installations to MV, HV and EHV power systems," 2008, no. 1, p. 9.

[23] IEEE, IEEE 1159 - Recommended Practice for Monitoring Electric Power Quality. 1995.

[24] IEEE, "IEEE PES AMPS DSAS Test Feeder Working Group," 2017. [Online]. Available: http://sites.ieee.org/pestestfeeders/resources/. [Accessed: 30-Nov-2018]. 